
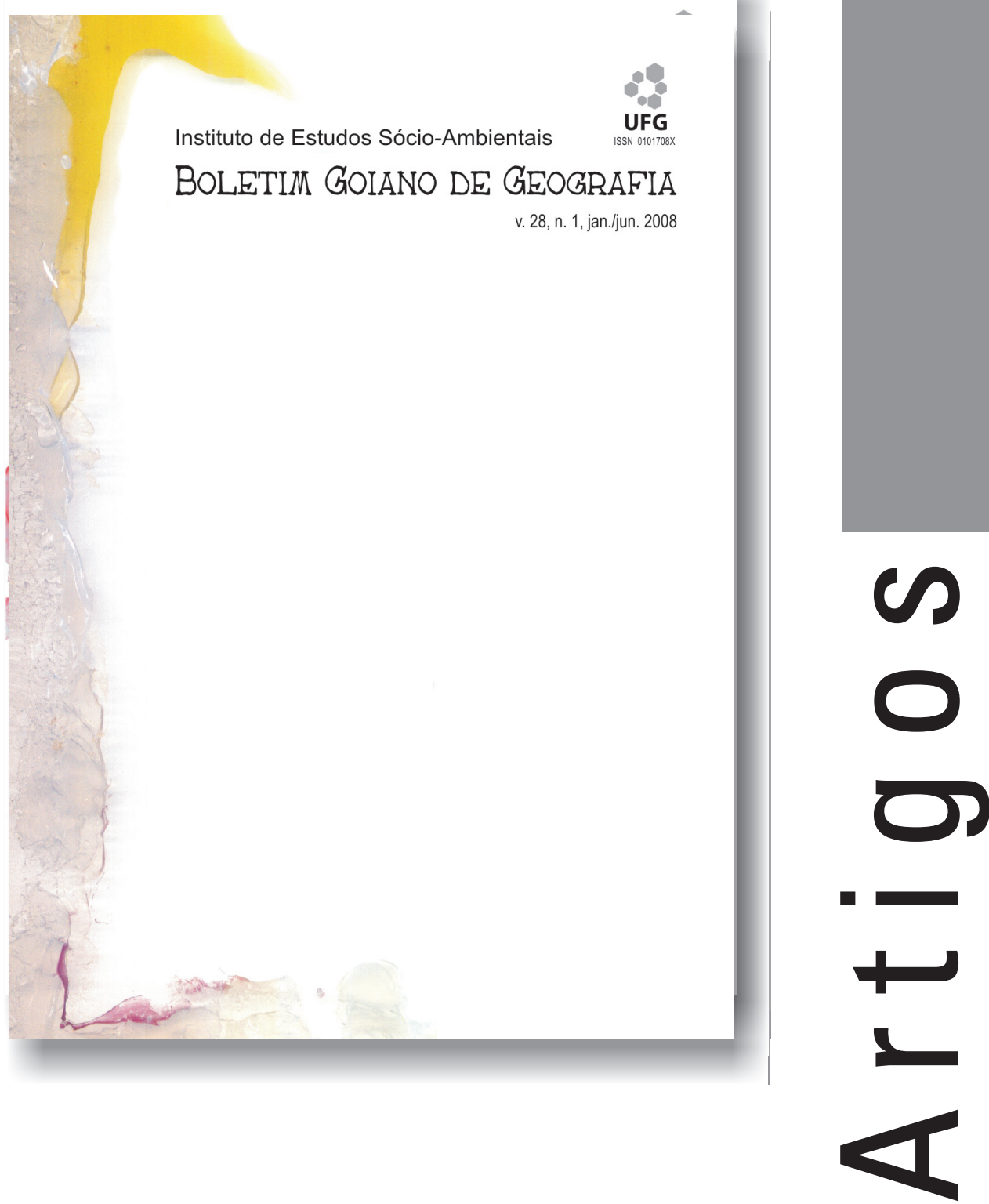


\title{
Raça e gênero sob uma perspectiva geográfica: espaço e representação
}

\author{
Race et genre sous un regard géographique: espace et répresentation
}

\author{
Lorena Francisco de Souza - Universidade Federal de Goiás \\ lorelune@yahoo.com.br
}

Alecsandro J. P. Ratts - Universidade Federal de Goiás

ratts@iesa.ufg.br

\section{Resumo}

Este artigo refere-se a uma reflexão sobre a mulher negra a partir das considerações feitas pela geografia do gênero, voltada para uma abordagem sobre a dimensão espacial das relações entre mulheres e homens. A metodologia utilizada para esta reflexão, resultado parcial de uma pesquisa de mestrado, uma revisão Referências e entrevistas, enfocando a história de vida de mulheres negras professoras de escolas públicas. Existe uma ligação entre as variáveis gênero, raça e espaço, o que significa dizer que há uma dimensão espacial das relações raciais e de gênero bem demarcadas e é por isso que há espaços em que determinados grupos sociais ou 0 indivíduo se sente $(\mathrm{m})$ habituado(s) e outros que thes são estranhos. Este trabalho pauta-se, portanto, em uma breve discussão sobre a espacialidade da mulher negra enquanto sujeito social no espaço urbano de Goiânia, e sobre as trajetórias socioespaciais percorridas por ela.

Palavras-chave: gênero, espaço, raça, geografia dos gêneros

\section{Résumé}

Cet article est une réflexion sur la femme noire à commencer pour les considérations faites pour la géographie du genre avec un abordage sur la dimension espacial des relations entre des femmes et des hommes. La méthodologie utilisée pour cette réflexion, résultat partiel d'une recherche du maîtrise, fut la révision bibliographique et des entrevues pour voir l'histoire de vie des femmes noires dans les écoles publiques. II y a une liaison entre les variables genre, race et l'espace, ça veux dire qu'il y a une dimension espacial des relations raciales et de genre bien signalées et c'est pour ça qu'il y a des espaces où déterminés groupes sociales ou des individus se sentent habitués et d'autres que les sont étranges. Ce travail fait, pourtant, une rapide discussion sur l'espacialité de la femme noire comme sujet social dans l'espace urbain de Goiânia et sur les trajectoires socioespaciales parcouris pour elles.

Mots-clé : genre, espace, race, géographie des genres

\begin{tabular}{|l|c|c|c|c|c|c|}
\hline Boletim Goiano de Geografia & Goiânia - Goiás - Brasil & v. 28 & n. 1 & p. 143-156 & jan. / jun. & 2008 \\
\hline
\end{tabular}




\section{Considerações iniciais}

O objetivo deste artigo é refletir sobre a condição da mulher negra a partir das considerações feitas pela geografia do gênero que aborda a dimensão espacial das relações de gênero. Segundo Claval (1999), estudos da geografia do gênero se apegam ao fato de que há diferenças culturais entre o masculino e o feminino na maneira de conceber o mundo e vivê-lo. Dessa forma, não podemos separar a categoria gênero das relações políticas, econômicas, sociais, culturais e raciais, pois é inconcebível um universo consensual entre as mulheres que desconsidera suas particularidades.

Ao longo da história ocidental, as mulheres negras ocuparam uma posição desfavorável no mercado de trabalho e foram atribuídos a estas espaços sociais demarcados, como a casa dos senhores, conseqüentemente, a dos patrões. Como salienta Ratts (2003a), existe uma interseção entre as categorias gênero, raça e espaço, o que significa dizer que há uma dimensão espacial das relações raciais e de gênero bem demarcadas e, nesta assertiva, há espaços em que determinados grupos sociais ou o indivíduo se sente(m) habituado(s) e outros que lhes são estranhos. Portanto, este trabalho pauta-se em uma breve discussão sobre a espacialidade da professora negra enquanto sujeito social em Goiânia e sobre as trajetórias socioespaciais percorridas por ela.

As trajetórias evocam, como afirma Certeau (1994), um movimento temporal no espaço, a unidade de sucessivos "pontos" percorridos, compreendidos como a casa, a escola, a rua, os ambientes freqüentados. A trajetória é desenhada por seus agentes sociais em questão, as professoras que traçam perspectivas, visões de mundo, esperanças e desesperanças. Uma das intenções da pesquisa de mestrado que deu origem a este artigo foi, como diz Certeau (1994), traçar e compreender os trajetos, os caminhos feitos e significados pelos sujeitos, buscando perceber como eles/elas representam o olhar a si mesmos/as e aos/às outros/as. As trajetórias socioespaciais demonstram as histórias de vida das professoras, abarcando as dificuldades socioeconômicas, a luta para fugir delas, os deslocamentos espaciais realizados, a espacialidade de suas práticas cotidianas e a dimensão espacial das relações raciais.

Santos (1996), quando discute a dimensão espacial do cotidiano, afirma que a informação e a comunicação no mundo atual alcançaram todos os aspectos da vida social, enriquecendo o cotidiano de novas dimensões. Daí "entre estas, ganha relevo a sua dimensão espacial, ao mesmo tempo em que 
esse cotidiano enriquecido se impõe como uma espécie de quinta dimensão do espaço banal, o espaço dos geógrafos” (1996, p. 257).

\section{Relações de gênero e raça}

A noção de espaço que permeia estas discussões é concebida como uma dimensão das relações sociais, não somente como suporte - espaço físico - e sim, como construção social (SANTOS, 1982) que porta elementos simbólicos e que pode ser derivada em outras noções a exemplo de paisagem, lugar, região ou território referentes. O espaço, conforme Santos,

(...) é a síntese, sempre provisória, entre o conteúdo social e as formas espaciais. Mas a contradição principal é entre sociedade e espaço, entre um presente invasor e ubíquo que nunca se realiza completamente, e um presente localizado, que também é passado objetivado nas formas sociais e nas formas geográficas encontradas (1982, p. 88).

A categoria espaço é a responsável pela reprodução da totalidade social, determinada por necessidades sociais, econômicas e políticas. Para Santos (1982), o espaço é a matéria trabalhada por excelência, pois nenhum outro objeto social se impõe tanto sobre o ser humano e suas ações: o espaço está no cotidiano. Afirma-se então que "a casa, o lugar de trabalho, os pontos de encontro, os caminhos que unem esses pontos, são igualmente elementos passivos que condicionam a atividade dos homens [e mulheres] e comandam a prática social” (SANTOS, 1982, p. 18).

A espacialidade de um grupo corresponde a um elemento identitário no sentido de que no espaço se configuram formas e ações próprias de um determinado grupo ou indivíduo. De acordo com D’Adesky (2001), o espaço contribui para uma leitura de significados sobre as representações coletivas, revelando relações de inclusão ou exclusão, hierarquias ou polaridades. Este autor salienta ainda que o comportamento de um indivíduo em cada local casa, escola, praça, locais de lazer - muda, pois cada um deles apresenta-se carregado de normas e hábitos aceitos e impostos pela sociedade. Assim, é possível notar as mutações de um individuo em cada um dos espaços que adentrar, o que faço é uma ligação com as professoras negras, à medida em que se posicionam em seus locais de trabalho, de militância política e lazer.

Trata-se aqui de fazer menção à relevância do estudo sobre o cotidiano dos agentes sociais, ao mesmo tempo em que se considera as diferenças 
sociais na produção do espaço. Segundo Cavalcanti (2001) falar de produção do espaço é referir-se a ele enquanto componente da produção social. Esta, por sua vez apresenta-se de forma dialética e contraditória, afirmando as diferenças de classe, em conseqüência, a segregação espacial. A segregação, segundo Villaça (1998), ao analisar as contradições do/no espaço urbano, se refere a um processo em que diferentes classes ou camadas sociais se concentram em regiões ou bairros diferentes de uma metrópole. Embora o intuito de nosso trabalho não seja discutir as contradições existentes na cidade, é imprescindível que consideremos a segregação espacial combinada à classe, raça e gênero.

Considerar as relações entre gênero, raça e espaço (RATTS, 2003a) é papel da ciência geográfica em consonância com outras ciências preocupadas em investigar as relações sociais e suas manifestações no espaço. No que concerne à investigação científica diante do ser mulher negra a partir dos estudos voltados à raça/etnia e gênero, verifica-se que há uma identidade que vem sendo reprimida ou camuflada ao longo dos tempos, como se fosse inútil firmar-se como mulher numa realidade social que garante o homem, sobretudo o homem branco, como detentor do poder, do conhecimento e ator hegemônico das mudanças vividas pela sociedade em geral, tanto em nível político, social, como também cultural.

Embora exista uma preocupação em algumas disciplinas das chamadas ciências humanas em discutir e compreender as relações entre o ser mulher e homem, entre o feminino e o masculino, o gênero é um elemento ainda pouco visto e discutido pela Geografia, mesmo sendo imprescindível na sociedade de classes. A raça/etnia também amplia o quadro de categorias que deveriam ser mais exploradas pela ciência geográfica em seu viés cultural. De acordo com o Ratts,

(...) o jogo de espelhos da identidade cultural, étnica ou racial - sempre contrastiva - nos remete para uma dimensão espacial e suscita análises geoculturais ou etnogeográficas. Há um campo a descortinar e interseções a fazer entre o étnico, o racial, o local, o regional, o nacional e o popular. Existe um terreno propício para que a Geografia se envolva com esse encontro/confronto teórico que implica em trazer etnia e raça para dentro de suas análises, assim como o fizemos com a "cultura" (2004, p. 85).

Consideramos a relação existente entre o gênero e a raça a partir de uma leitura socioespacial sustentada por algumas categorias de análise geográficas, como o espaço e a trajetória socioespacial, considerando os grupos socialmente segregados, aqui representados pelas mulheres negras. 
A Geografia procura ampliar os estudos e análises sobre o ser humano, enquanto indivíduo ou grupo social, superando a perspectiva global de se preocupar com a descrição da terra, das paisagens imbuídas nela e das formas de organização do espaço desenvolvidas. Sendo assim, ela busca interrogar os seres humanos sobre suas experiências vividas, analisar as dimensões espaciais das relações entre os atores sociais que afirmam suas personalidades e modos de vida.

Para Claval, (2001) torna-se imprescindível à Geografia assumir o papel de esclarecer a dinâmica dos comportamentos humanos, flexíveis graças às diferentes concepções filosóficas e visões de mundo. Segundo o autor, a transformação dos estudos culturais na Geografia partiu da reflexão sobre as realidades responsáveis pela organização social de um povo ou indivíduo e por seu modo de vida, incluindo aí suas atividades impregnadas de imaterialidade.

Com a abordagem humanista na Geografia, os estudos culturais tomam uma dimensão importante nesta ciência, e atualmente, uma interpretação acerca das relações raciais e de gênero no espaço urbano tem chamado a atenção para aspectos interdisciplinares que ajudam a analisar e compreender as relações sociais (SANTOS, 1996, 2000, 2002), CAMPOS (2005), SILVA (2005).

De acordo com a cultura de uma sociedade, leis e costumes são estabelecidos, bem como relações de poder entre opressor(a) e oprimido(a). Nossa cultura, baseada em um referencial patriarcal, sexista e racista, propaga uma dita inferioridade ou vulnerabilidade da mulher com relação ao homem, sustentada por uma interpretação das diferenças biológicas e, juntamente, a inferiorização da raça segundo o gênero.

Atualmente, é notório o aumento do número de trabalhos que objetivam atingir uma inter e transdisciplinaridade, o que ressalta a importância de outras ciências na construção dos estudos geográficos sobre cultura. Tal mergulho conceitual em outras ciências tem rendido críticas de geógrafos não-culturalistas sobre o ecletismo a que a Geografia tem se rendido, já que, como salienta Seemann (2003), a geografia cultural procura cobrir questóes referentes desde as análises dos objetos que permeiam o cotidiano, a representação da arte e do cinema, o significado das paisagens até, dentre outros, o estudos sobre a identidade baseada nos lugares.

A aparente impossibilidade de atribuir definições de cultura e geografia para cumprir ditames acadêmicos ofusca o que é realmente relevante ao geógrafo voltado para as questões ditas culturais. De acordo com Seemann 
(2003), o importante é o fato de o/a geógrafo/a saber que a cultura é uma construção social constituída espacialmente e, principalmente, ter a certeza de que a geografia é fundamental para a verdadeira constituição da cultura.

Os sujeitos ligados à geografia devem compreender que a cultura, num sentido geral, é uma construção imaginada por indivíduos ou por uma sociedade, com a finalidade de estabelecer ligações e hábitos em comum. Não cabe ao/à geógrafo/a explicar o inexplicável nas relações humanas e sociais, mas sim questionar as ações e representações calcadas em mitos, em preconceitos construídos por meio de um processo histórico que perduram nos tempos atuais, demarcando vantagens de grupos dominantes sobre os dominados.

Uma das contribuições da geografia no questionamento sobre a realidade social excludente, que hierarquiza indivíduos de acordo com sua cor, classe social e gênero, é o interesse cada vez maior por temáticas antes desconsideradas, já que não se tratavam do "fazer geográfico". A chamada geografia dos gêneros ${ }^{1}$ e a geografia feminista ${ }^{2}$ têm sido um campo de interesse para estudiosos(as) latino-americanos(as), e a preocupação em refletir sobre as condições da mulher num mundo majoritariamente misógino se faz presente no discurso de importantes movimentos sociais do mundo inteiro, principalmente, o feminista.

A geografia do gênero tem como foco principal analisar as relações existentes entre espaço e gênero, determinando papéis e funções dos gêneros, a divisão do trabalho e as relações de poder entre eles. As relações de gênero, segundo Martinez, Moya e Muñoz (1995), fazem referência às relações de poder existentes entre homens e mulheres. Geralmente, em âmbitos espaciais, culturais e temporais existe uma relação de subordinação das mulheres com relação aos homens, o que incita a ciência a fazer reflexões consistentes sobre a visão de mundo sexista.

Como afirma Almeida (1998), o campo epistemológico das ciências humanas, até atualmente, tem sido omisso em relação à categoria gênero, "dado que o androcentrismo que permeia as construções teóricas das ciências sempre relegou os feitos femininos a um plano praticamente inexistente" (1998, p.44). A suposta neutralidade sexual das ciências tem, na verdade, demonstrado negligência em adotar uma categoria de análise tão importante, e tem sido conivente com as imposições misóginas de "fazer ciência". De acordo com Silva (2005), a produção do conhecimento geográfico acerca do gênero tem apresentado dificuldades devido ao androcentrismo que impede uma análise espacial na perspectiva feminina. 
Nas dimensões geográficas, a mulher não pode ser vista apenas como constituinte de um gênero, mas também da sexualidade, da raça, da religião e da classe social. Tais elementos são vividos simultaneamente, o que nos faz reconhecer a existência de uma pluralidade de feminilidades. Sob o reconhecimento dos elementos materiais e simbólicos nas relações de gênero e espaço, pesquisadores/as geógrafos/as podem ir além da análise sobre o espaço da reprodução, e revogarem o espaço da transformação (SILVA, 2005).

O uso da categoria gênero serviu para diferenciar-se da categoria sexo, pois as diferenças entre homens e mulheres corresponderiam a uma construção social e não a uma especificidade sexual biológica. A palavra gênero passou a ser usada nos movimentos feministas com o intuito de buscar uma explicação para a subordinação das mulheres (PEDRO, 2005) e as transformações sofridas pelo movimento feminista, ao longo dos anos priorizaram termos e reivindicações de acordo com o contexto vivido. Enquanto no final do século XIX o movimento feminista europeu reivindicava direitos políticos e trabalho remunerado (PINSKY e PEDRO, 2003) após a Segunda Guerra foi priorizado o direito sobre o corpo. Neste contexto, a palavra gênero ainda não era utilizada, mas sim "mulher" em contraposição ao uso do termo "homem" que era o representante universal nas referências sobre o ser humano, o que continua sendo comum nos tempos atuais. O termo gênero passou a corresponder às afirmações que compreendiam as relações desiguais entre homens e mulheres como construções a partir de um discurso social que explica as funções destinadas a cada uma(um).

Existe uma construção de feminilidade e masculinidade atribuída a mulheres brancas e negras. A construção de identidades de gênero deu-se pela repetição da interpretação da diferença entre mulheres e homens, feminilidade e masculinidade, e também, pela constante afirmação de que há uma oposição hierárquica entre feminilidade e falta de feminilidade, entre masculinidade e falta de masculinidade (PRINS e MEIJER, 1999).

Os estudos de gênero também têm sido adotados por estudiosos(as) da questão racial, o que alavancou o surgimento de trabalhos sobre as mulheres negras e as relações de subordinação que as categorias gênero e raça acarretam. De acordo com Stolcke (1991), no plano da militância, as mulheres negras, não satisfeitas com a invisibilidade no movimento feminista de mulheres brancas, acrescentaram uma maneira diferente de "abordar a maneira como gênero, classe e raça se cruzam pra criar não apenas fatores comuns, mas também diferenças na experiência das mulheres" (1991, p. 102). Estudos que abarcam categorias gênero e raça focalizam manifestações 
de mulheres negras a respeito de suas vivências que situam as dimensões do ser cidadãs numa sociedade que discrimina o grupo de gênero e o de raça a que pertencem.

\section{Espaço e cultura: gênero e raça no urbano}

Segundo Carneiro (2003), a variável racial produziu gêneros subalternizados, tanto no que toca a uma identidade feminina estigmatizada, como a das mulheres negras, quanto à masculinidade subalternizada dos homens negros com prestígio inferior ao do gênero feminino do grupo racialmente dominante correspondente às mulheres brancas. Essa assertiva quer dizer que há uma subalternização da raça segundo o gênero, pois, historicamente, mulheres negras foram consideradas como um tipo masculinizado de mulher enquanto os homens negros não foram vistos como um ideal de homem dominador, detentor de poder, provedor ou chefe.

A representação da mulher negra na sociedade brasileira contemporânea provém do processo histórico da colonização que permanece em outros moldes. No Brasil-Colônia, a função da "mulher de cor" se restringia ao trabalho na lavoura, aos afazeres domésticos, à manutenção da cozinha e bem-estar da "sinhá", como ama ou mãe preta, além de objeto sexual dos senhores de escravos, salvo algumas exceções de escravas libertas, mucamas e vendedoras (SAFFIOTTI, 1979; GONZÁLEZ, 1984;). Porém, passados séculos do escravismo no Brasil, é comum presenciar-se nos dias de hoje a analogia entre as atividades da mulher negra daquela época e a mulher negra inserida na economia de mercado atual. Sendo assim, torna-se comum reproduzir a idéia de que a cozinha e o trabalho doméstico, principalmente, são os espaços sociais por excelência da mulher negra.

É imprescindível questionar a presença ou ausência destas mulheres negras em locais públicos, como a escola enquanto lugar de trabalho, e privados, como nos momentos de lazer ou com a família. Dessa forma, questionamos em que medida alguns espaços vão se delimitando como acolhedores da "sociedade branca" (SANTOS, 2002) em detrimento da população negra. De que forma as relações raciais apresentam certa dimensão espacial? Como se configuram as relações de gênero em âmbitos espaciais também demarcados? Qual a relação da mulher negra com o espaço em que vive, incluindo aí as relações sociais e o perfil da sociedade que a cerca e da qual faz parte? 
Na busca por subsídios para uma reflexão a partir destes questionamentos, é possível reinterpretar o mito da democracia racial em sua dimensão geográfica em que se percebe a existência de segregação espacial combinada com segregação étnico-racial. Trata-se igualmente de constituir um saber que conjugue a reflexão sobre raça com a(s) teoria(s) acerca do espaço.

O espaço é elemento constitutivo e produto de encontros/confrontos étnicos e raciais e a unidade de análise pode variar do território nacional à habitação familiar (RATTS, 2004). Contribuições de Léfèbvre (apud Corrêa, 2005) apontam para o fato de que o espaço é o lócus da reprodução das relações sociais de produção ou, em outras palavras, da sociedade. A assertiva de que o espaço é social também inspirou Milton Santos (1982) quando se refere à formação socioespacial, sendo esta um ponto para explicar que "uma sociedade só se torna concreta através de seu espaço, do espaço que ela produz e, por outro lado, o espaço só é inteligível através da sociedade" (SANTOS, 1982, p. 26). Não é viável falar de sociedade sem falar de espaço e vice-versa, portanto, a categoria formação socioespacial permite uma concepção paradigmática no sentido de que o espaço é mais que um reflexo social e sim um fator social.

A corrente humanista e cultural na Geografia priorizou categorias como paisagem, região e lugar, já que a subjetividade, a intuição, os sentimentos, a experiência eram, sob essa perspectiva, elementos fundamentais para a compreensão do mundo real. As noções de espaço sob essa corrente filosófica firmavam-se e firmam-se, sob a definição de espaço vivido enquanto um campo de representações simbólicas imbuídas de sentimentos e afetividades lançadas por grupos sociais.

No entanto, estudos voltados ao espaço urbano permitem uma transitoriedade sobre noções de espaço vivido e de reprodução das relações sociais numa perspectiva em que se possam ser reveladas "as práticas sociais dos diferentes grupos que nele produzem, circulam, consomem, lutam, enfim, vivem e fazem a vida caminhar" (CORRÊA, 2005). É na cidade que se configuram as relações sociais (CAVALCANTI, 2001), que se fragmenta a sociedade por meio de aspectos sociais, culturais, raciais e de gênero, portanto, não me ausentei do espaço urbano para enfocar contradições e espacialidades vividas, diferenciadas por mulheres negras, que convivem com a segregação socioespacial em Goiânia.

A afirmação de que existe segregação espacial combinada à segregação étnico-racial possibilita uma discussão sobre trajetórias vividas por professoras negras em questão, bem como sobre os deslocamentos espaciais 
percorridos ao longo de seu cotidiano no percurso casa-universidade- trabalho e lazer. A escola também foi fundamental para o acompanhamento das trajetórias socioespaciais das mulheres negras professoras, e para a construção do sentimento de pertencimento das mesmas em determinados espaços, tanto públicos quanto privados.

Estas mulheres, ao longo de suas vidas, percorreram caminhos além da cidade natal, migraram para um centro urbano em busca de oportunidades de emprego e de estudo, firmaram-se enquanto profissionais da educação, puderam adentrar a universidade e construir um percurso educacional diferente da maioria das mulheres negras em nosso país. Esses caminhos feitos, o acompanhamento das trajetórias a partir da história de vida dessas mulheres aqui são designados como deslocamentos socioespaciais que incitam uma idéia de mobilidade social e espacial.

\section{Considerações finais}

A compreensão das relações sociais de mulheres negras no ofício de professoras com a comunidade escolar, a família e demais atores sociais envolvidos permite uma reflexão sobre como um determinado grupo pensa seu espaço, quais as suas representações sobre o mundo e sua realidade, além de investigar a vivência em seus "espaços", ultrapassando o simples ato de descrever lugares e momentos para interpretar espacialidades e temporalidades a partir da observação sensível e crítica de um determinado grupo social (RATTS, 2003b).

Procuramos enfocar a história de vida, um segmento da história oral, como elemento indispensável, já que o grupo racial envolvido tem fundamental importância e encaminha reflexões no âmbito geográfico como em alguns de nossos trabalhos (SOUZA, 2007; RATTS, 2004, 2003a). A história oral é uma metodologia que aprofunda relações entre memória e história, entre história oral e história do tempo presente, entre tipos de entrevistas e formas de narrar trajetórias individuais, as chamadas histórias de vida (AMADO e FERREIRA, 1996). Como ratifica Medeiros (1987), "centrar no indivíduo o fulcro da investigação mostrou ser um processo extremamente rico, pela profundidade dos traços sugeridos" (1987, p. 207).

O enfoque racial e de gênero na ciência geográfica pauta-se na possibilidade de instigar demais sujeitos preocupados/as com a temática racial e de gênero na busca de questionar mitos e repensar as práticas racistas que 
são frutos das representações sociais estereotipadas. Nosso trabalho visa, antes de tudo, divulgar a voz de mulheres que fazem da palavra e da ação uma arma na luta anti-racista e inscrevem suas trajetórias no espaço urbano de Goiânia.

\section{Notas}

1 Embora pouco explorado pelos geógrafos, o termo é usado por aqueles (as) que trabalham com a relação entre gênero, trabalho, território (GARCIA, 2002) e cultura (CLAVAL, 1999).

2 Segundo Silva (2005) esta vertente geográfica quer compreender como o sujeito feminino é construído nas estruturas de dominação socioespaciais. A autora salienta que o ambiente construído reflete os estereótipos dos lugares femininos e masculinos e o jogo de forças empreendido em seu processo de produção.

\section{Referências}

ALMEIDA, Jane Soares de. Mulher e Educação: a paixão pelo possível. São Paulo: Editora UNESP, 1998.

AMADO, Janaína; FERREIRA, Marieta de Moraes. Apresentação. In: . Usos e abusos da História Oral. Rio de Janeiro: Editora da Fundação Getúlio Vargas, 1996.

CAMPOS, Andrelino. Do quilombo à favela: a produção do "espaço criminalizado" no Rio de Janeiro. Rio de Janeiro: Bertrand Brasil, 2005.

CARNEIRO, Sueli. Mulheres em movimento. Estudos Avançados, São Paulo, vol.17, n. 49, Setembro/Dezembro, 2003. pp.117-133.

CAVALCANTI, Lana de Souza. Uma geografia da cidade - Elementos da produção do espaço urbano. In: . (org.). Geografia da Cidade: A produção do espaço urbano de Goiânia. Goiânia: Alternativa, 2001.

CERTEAU, Michel de. A invenção do cotidiano: Artes de fazer. Trad. Ephraim F. Alves. Petrópolis, RJ: Vozes, 1994.

CORREAA, Roberto Lobato. Espaço: um conceito-chave da Geografia. In: CASTRO, Iná E. de; GOMES, Paulo C. da C; CORRÊA, Roberto L. Geografia: conceitos e temas. Rio de Janeiro: Bertrand Brasil, 2005. pp. 15-48.

CLAVAL, Paul. A Geografia Cultural: O estado da arte. In: ROSENDAHL, Zeny; CORRÊA, Roberto L. (orgs.). Manifestações da cultura no espaço. Rio de Janeiro: EdUERJ, 1999, pp.59-57.

. O papel da nova Geografia Cultural na compreensão da ação humana. In: ROSENDAHL, Zeny; CORRÊA, Roberto L. (orgs.). Matrizes da Geografia Cultural. Rio de Janeiro: EdUERJ, 2001, pp.35-86.

D'ADESKY, Jacques. Pluralismo étnico e multiculturalismo: racismos e anti-racismos no Brasil. Rio de Janeiro: Pallas, 2001. 
GARCIA, Maria F.; JÚNIOR, Antonio T. Trabalhadoras rurais e luta pela terra no Brasil: interlocução entre gênero, trabalho e território. Terra Livre, São Paulo, ano 18, n. 19, jul./dez. 2002, pp. 257-272.

GONZALEZ, Lélia. Racismo e sexismo na cultura brasileira. Revista Ciências Sociais Hoje, ANPOCS, Rio de Janeiro, 1984.

MARTÍNEZ, Ana S.; MOYA, Juana Mª. R.; MUÑOZ, Ma . Ángeles D. Mujeres, Espacio y Sociedad: Hacia una geografía del género. Madrid: Editorial Síntesis, 1995.

MEDEIROS, Maria Alice de A. Mulheres negras: histórias de vida. Revista de Ciências Sociais, Rio de Janeiro, v. 30, n. 2, 1987, pp. 207-222.

PEDRO, Joana Maria. Traduzindo o debate: o uso da categoria gênero na pesquisa histórica. História, São Paulo, v. 24, n. 1, 2005. pp. 77-98.

PINSKY, Carla B.; PEDRO, Joana Maria. Mulheres: igualdade e especificidade. In: PINSKY, Jaime; PINSKY, Carla B. (orgs.) História da cidadania. São Paulo: Contexto, 2003. pp. 264-309.

PRINS, Baukje; MEIJER, Irene Costeira. Como os corpos se tornam matéria: entrevista com Judith Butler. Estudos Feministas, Florianópolis: UFSC, v.10, n.1, 2002. pp.155-169

RATTS, Alecsandro J. P. As etnias e os outros: as especialidades dos encontros/confrontos. Espaço e Cultura, UERJ, Rio de Janeiro, n. 17-18, jan./dez. de 2004. pp. 77-89.

. Gênero, raça e espaço: trajetórias de mulheres negras. Comunicação apresentada no XX Encontro Nacional da ANPOCS, Caxambu-MG, out. 2003a.

. A geografia entre as aldeias e os quilombos: Territórios etnicamente diferenciados. In: ALMEIDA, Maria G. de; RATTS, Alecsandro J. P. (orgs.) Geografia: leituras culturais. Goiânia: Alternativa, 2003b. pp. 29-48.

SAFFIOTI, Heleieth. A evolução da condição da mulher no Brasil. In: A mulher na sociedade de classes: mito e realidade. Petrópolis: Vozes, 1979. pp. 134-255.

SANTOS, Milton. Ser negro no Brasil hoje. In: SANTOS, Milton. O país distorcido: o Brasil, a globalização e a cidadania. São Paulo: Publifolha, 2002, pp.157-161.

. As exclusões da globalização: Pobres e Negros. In: FERREIRA, Antônio Mário (org.). Na própria pele: os negros no Rio Grande do Sul. Porto Alegre: CORAG/Secretaria de Estado da Cultura, 2000, pp.9-20.

. Sociedade e espaço: a formação social como teoria e como método. In: Espaço e Sociedade: Ensaios. Petrópolis: Vozes, 1982, pp. 9-22. $250-274$

A força do lugar. In: A natureza do espaço. São Paulo: HUCITEC, 1996. pp.

SEEMANN, Jörn. Mapeando culturas e espaços: uma revisão para a Geografia Cultural no Brasil. In: ALMEIDA, Maria G. de; RATTS, Alecsandro J. P. (orgs.) Geografia: leituras culturais. Goiânia: Alternativa, 2003a, pp. 261-284.

SILVA, Joseli Maria. Análise do espaço sob a perspectiva do gênero: um desafio para a geografia cultural brasileira. In: ROSENDAHL, Zeny; CORREAA, Roberto L. (orgs.). Geografia: temas sobre cultura e espaço. Rio de Janeiro: EdUERJ, 2005, pp.173-189. 
SOUZA, Lorena Francisco de. Corpos negros femininos em movimento: trajetórias socioespaciais de professoras negras em escolas públicas. Goiânia: UFG, 2007. 126 p. Dissertação de mestrado em Geografia - Instituto de Estudos Sócio-Ambientais, Universidade Federal de Goiás, 2007.

STOLCKE, Verena. Sexo está para gênero assim como raça para etnicidade?. Estudos AfroAsiáticos, n.20, 1991.

Lorena Francisco de Souza - Licenciada e Mestre em Geografia - Universidade Federal de Goiás e professora substituta do IESA-UFG

Alecsandro J. P. Ratts - Doutor em Antropologia e professor do IESA/UFG

Recebido para publicação em abril de 2008

Aceito para publicação em maio de 2008 